\title{
Proposta Pedagógica de Ensino Médico na Atenção Básica: relato de experiência
}

\author{
Pedagogical Proposal of Medical Teaching in Primary Health: experience report \\ Propuesta pedagógica en la enseñanza médica en atención primaria: informe de \\ experiencia
}

Juliana de Gregório Oliveira ${ }^{1}$, Lucia Cardoso Mourão ${ }^{1}$, Ana Clementina Vieira de Almeida ${ }^{1}$, Núncio Antônio Araújo Sol ${ }^{1}$, Vilma Vieira da Silva ${ }^{1}$, Lucille Annie Carstens ${ }^{1}$, Pedro Sanches Corrêa ${ }^{1}$.

\section{RESUMO}

Objetivo: Relatar a experiência de aplicação de uma estratégia pedagógica para os primeiros períodos da formação médica nos serviços de saúde com foco na humanização da assistência junto à gestante. Relato da experiência: esta estratégia foi aplicada junto a dois grupos de alunos do segundo ano de graduação em Medicina, de uma universidade pública do Rio de Janeiro, no ano de 2018. Os alunos vivenciaram, na prática, quatro momentos que permitiram ampliar as reflexões sobre a humanização, a saber: consulta médica; visita domiciliar; grupos educativos e visita à maternidade. Todas as observações referentes aos momentos vivenciados pelos participantes foram registradas no diário de pesquisa da primeira autora. $A$ utilização do diário apoiou-se nos pressupostos da Análise Institucional, que considera o diário um instrumento de coleta de dados, permitindo a análise das implicações pessoais e profissionais dos participantes com a formação médica e a humanização da assistência. Considerações Finais: como potencialidades desta experiência, destaca-se a oportunidade de os alunos vivenciarem e refletirem sobre diferentes maneiras de cuidar pautadas nos princípios da humanização. O principal desafio está na mudança de postura dos profissionais e de educadores, em suas práticas de ensino, para a formação dos futuros profissionais.

Palavras-chave: Educação médica, Saúde da mulher, Humanização da assistência.

\begin{abstract}
Objective: Report the experience of applying a pedagogical strategy for the first periods of medical education in health services focusing on the humanization of care with pregnant women. Experience report: this strategy was applied to two groups of undergraduate medical students from a public university in Rio de Janeiro in 2018. In practice, the students experienced four moments that allowed broadening the reflections on humanization, namely: medical appointment; home visit; educational groups and maternity visit. All observations regarding the moments experienced by the participants were recorded in the first author's research journal. The use of the diary was based on the assumptions of Institutional Analysis, which considers the diary as a data collection instrument, allowing the analysis of the participants' personal and professional implications with medical training and humanization of care. Final considerations: as potentialities of this experience, we highlight the opportunity for students to experience and reflect on different ways of caring based on the principles of humanization. The main challenge lies in changing the attitude of professionals and educators, in their teaching practices, for the training of future professionals.
\end{abstract}

Key words: Medical education, Women's health, Humanization of assistance.

1Universidade Federal Fluminense (UFF). Niterói-RJ. *E-mail: ana.vieiradealmeida@gmail.com. 


\section{RESUMEN}

Objetivo: Reporter la experiencia de aplicar una estrategia pedagógica para los primeros períodos de educación médica en servicios de salud enfocados en la humanización de la atención a mujeres embarazadas. Informe de experiencia: esta estrategia se aplicó a dos grupos de estudiantes de medicina del pregrado de una universidad pública en Río de Janeiro en 2018. En la práctica, los estudiantes experimentaron cuatro momentos que permitieron ampliar las reflexiones sobre la humanización. a saber: cita médica; visita a domicilio; grupos educativos y visita de maternidad. Todas las observaciones sobre los momentos experimentados por los participantes se registraron en el primer diario de investigación del autor. El uso del diario se basó en los supuestos del análisis institucional, que considera el diario como un instrumento de recopilación de datos, lo que permite el análisis de las implicaciones personales y profesionales de los participantes con la capacitación médica y la humanización de la atención. Consideraciones Finales: como potencialidades de esta experiencia, destacamos la oportunidad para que los estudiantes experimenten y reflexionen sobre diferentes formas de cuidado basadas en los principios de la humanización. El principal desafío radica en cambiar la actitud de los profesionales y educadores, en sus prácticas docentes, para la formación de futuros profesionales.

Palabras clave: Educación médica, Salud de la mujer, Humanización de la asistencia.

\section{INTRODUÇÃO}

A institucionalização do Sistema Único de Saúde (SUS), conquistada pelos setores progressistas da população brasileira, garantindo o direito à saúde, mudou os cenários de aprendizagem dos profissionais de saúde, redirecionando a formação médica tradicional, centrada na prática hospitalar da cura de doenças, para uma clínica ampliada que valoriza a formação generalista, humanista e crítico-reflexiva na rede de assistência à saúde (SILVA LA, et al. 2015). Dessa forma, coloca-se como desafio, aos centros formadores no ensino da Medicina, a necessidade de reformular práticas pedagógicas para formar profissionais aptos a exercerem suas funções, considerando princípios éticos, humanos e sociais.

Segundo Santos Júnior CJ, et al. (2019), há a necessidade de promover mudanças pedagógicas que aproximem os conteúdos ensinados na graduação em Medicina com as práticas cotidianas dos profissionais de saúde. $O$ autor defende ainda a oportunidade de estudantes, preceptores e professores terem experiências em cenários que possibilitem, aos futuros profissionais, a compreensão das dificuldades e possibilidades da gestão, da equipe de saúde e da população, o que aumenta as chances de atuar efetivamente na resolução dos desafios inerentes ao exercício profissional.

Neves SAVM, et al. (2016) referiram que as novas Diretrizes Curriculares Nacionais (DCN) do curso de Medicina, de 2014, reorientam as mudanças na educação médica, voltando-a para práticas humanizadas, críticas, reflexivas, integradas ao SUS e investindo em currículos que fortaleçam as dimensões culturais, estéticas, sociais e históricas. Estas recomendam o desenvolvimento de atividades que promovam a inserção dos alunos na realidade social da maioria da população brasileira para que - por meio de observações, diálogos e reflexões - eles possam adquirir valores e conhecimentos técnicos que contribuam para uma formação mais humanizada.

Com a estruturação da rede de serviços do SUS, por meio da Estratégia Saúde da Família (ESF), os médicos foram apresentados a uma lógica de cuidado e a uma organização do processo de trabalho diferentes das quais estavam acostumados (BRASIL, 1990). A responsabilidade do médico com a formação dos futuros profissionais e com a sua educação permanente é incorporada às suas atribuições. Para tanto, algumas habilidades necessitaram ser desenvolvidas (VILAS BOAS LM, et al., 2017).

Neste sentido, é significativo observar o compromisso das escolas médicas em adaptar, ao longo dos anos, o processo de aprendizagem a um modelo de formação que considera os direitos constitucionais à saúde, formando médicos capazes de articular as práticas com os ideais da Política Nacional de Humanização (PNH) preconizados pelas referidas diretrizes (VILAS BOAS LM, et al., 2017). 
Segundo Menezes ML e Santos LRCS (2017), a PNH desempenha um papel modelador do arcabouço ideológico, teórico e operacional nas organizações do serviço de saúde, estimulando a reformulação das práticas e priorizando o desenvolvimento da autonomia dos participantes e a troca de saberes, para a construção do cuidado, de maneira multidisciplinar e intersetorial.

O curso de Medicina da universidade federal ao qual se refere neste relato oferece uma disciplina teóricoprática, desenvolvida no módulo da ESF - a partir de uma diretriz de diversificação de cenários de aprendizagem -, em convênio com a Secretaria Municipal de Saúde. Propõe a inserção dos alunos na Atenção Primária à Saúde (APS), desde os períodos iniciais do curso, com o objetivo de promover o contato, a vivência e a reflexão sobre as práticas e ações de saúde em suas dimensões políticas, econômicas, éticas, sociais, culturais, epidemiológicas e de gestão.

Neste relato, analisou-se a implementação de uma estratégia pedagógica para a referida disciplina construído e desenvolvido pela médica/preceptora e mestranda do Programa de Mestrado Profissional de Ensino em Saúde (MPES). A segunda autora, docente da universidade, supervisiona os alunos de graduação e orienta o referido estudo. Conta-se, ainda, com a participação da terceira autora, que é docente e pesquisadora do MPES, com experiência em pesquisas-intervenção, e dos demais autores, pesquisadores e alunos do mestrado profissional. Todos participaram do processo da elaboração deste artigo em todas suas fases. A relevância deste relato justifica-se por trazer contribuições ao ensino médico, buscando enfrentar as dificuldades de aprendizagem dos alunos em formação.

Em vista do exposto, este artigo objetiva relatar a experiência de aplicação de uma estratégia pedagógica para os primeiros períodos da formação médica nos serviços de saúde com foco na humanização da assistência junto à gestante.

\section{RELATO DA EXPERIÊNCIA}

Esta experiência foi desenvolvida no ano de 2018 com dois grupos de alunos do segundo ano de Medicina, totalizando 11 participantes, que cursavam a disciplina de Trabalho de Campo Supervisionado, da universidade federal, em uma unidade da ESF da região metropolitana II, do Estado do Rio de Janeiro, após aprovação no Comitê de Ética em Pesquisa (parecer n.ำ 2.849.667).

Os alunos foram convidados a participar de uma metodologia de aprendizagem em quatro momentos: consulta médica; visita domiciliar; grupos educativos e visita à maternidade. A metodologia foi aplicada a dois grupos totalizando oito encontros de vivências nas estratégias pedagógicas e oito encontros para debates sobre a humanização e a formação. A experiência metodológica foi finalizada com um encontro contando com a participação de toda equipe da ESF para ampliar os debates. Todos os momentos foram registrados no diário da pesquisadora

As estratégias pedagógicas foram aplicadas na linha de cuidado à saúde das gestantes, por ser esse o grupo populacional que tem o acompanhamento mais organizado em todos os níveis de complexidade da rede municipal de saúde do município cenário do estudo. Diante da necessidade de cumprir os padrões solicitados por esta revista, neste artigo, apresentar-se-ão duas estratégias, entendendo que as demais, ainda que tragam suas especificidades, seguiram a mesma linha de análise e discussão dos resultados.

Iniciamos o relato com fragmentos extraídos do diário da pesquisadora, durante a vivência da consulta médica com os alunos. Destaca a pesquisadora/preceptora em seu diário:

Reuni os alunos, antes da gestante entrar no consultório, e contei um pouco da sua história familiar. Na ESF, temos a oportunidade de aprofundar esse conhecimento, criando vínculo, permitindo maior fluidez da consulta, mostrando a importância de deixá-la segura para interagir. Antes de introduzir a gestante no consultório, perguntei se ela permitia a presença dos alunos. Ela disse que autorizava. Então, expliquei, aos alunos, as etapas da consulta. Notei a expectativa deles em examiná-la antes de tudo, enquanto eu me alongava no diálogo, abordando coisas comuns, até chegar às 
queixas ligadas à sua gestação. Os alunos observaram atentos. Iniciei o exame físico e percebi como o comportamento dos alunos se modificou; ficaram mais interessados como se não quisessem perder nenhum momento. Perguntei à gestante se autorizava que os alunos, sob a minha orientação, podiam examiná-la. Ela permitiu e notei que os olhos deles brilharam, apesar de parecerem assustados. Um a um foram se apresentando, conversando e examinando-a.

Complementa a pesquisadora/preceptora que:

Ao vivenciar a consulta médica com os alunos, coloco em prática os princípios da $\mathrm{PNH}$ e percebo como eles se surpreendem com a fluidez da consulta. Os alunos se mostram mais tranquilos para ouvir, o que diminui a pressa em examiná-la.

Após a consulta médica, os alunos e a pesquisadora/preceptora reuniram-se para debates e a mesma relatou em seu diário:

Uma das primeiras coisas que os alunos falaram foi o diferencial do atendimento médico. Assinalaram como significativo o fato do médico conhecer a paciente, onde ela morava e sua família. Afirmaram que isto foi fundamental para a criação de vínculo. Destacaram que foi interessante o jeito como chamei a gestante, pelo nome e com um sorriso... e não como "a próxima". Destacaram que foi por conta desta abordagem que a gestante se mostrou tão cooperativa, contando tudo e tirando suas dúvidas. Não imaginavam que todas aquelas perguntas seriam necessárias para uma consulta de pré-natal. Relataram, que sabendo informações sobre o grupo familiar e as condições de moradia, realmente fica mais fácil entender certas demandas, e junto com a gestante encontrar uma solução para os problemas de saúde.

A segunda estratégia pedagógica foi a visita domiciliar, que, no Brasil, consta nas atividades da ESF, permitindo que $o$ atendimento e o acompanhamento da população adscrita sejam realizados em seu local de residência (ROCHA KB, et al., 2017). Relata a primeira autora em seu diário:

Reunimo-nos na unidade, antes da visita, e conversei com os alunos sobre alguns aspectos importantes que devemos observar no campo de estágio e principalmente como deveríamos nos comportar diante de algumas situações. Enfatizei a importância de se pedir a permissão da gestante para entrar na residência e também o cuidado que deveriam ter se quisessem sugerir alguma mudança de hábitos e/ou comportamentos. Fizemos até uma dramatização, simulando uma conversa entre eles e os prováveis moradores, para ressaltar algumas recomendações. Foi uma maneira de ensinar divertida e os alunos entenderam que não poderíamos ir entrando na casa das pessoas e querendo modificar tudo autoritariamente.

Expliquei que podemos ajudar nas escolhas, mas a decisão final de como cuidar da saúde é sempre de cada indivíduo e de sua família. Os alunos entenderam como a postura deles poderia contribuir para o sucesso da visita e como a observação poderia ajudar a identificar problemas e a buscar possíveis soluções. Durante a visita, orientamos sobre a importância dos cuidados com o recém-nascido, do teste do pezinho, das vacinas e conversamos sobre as questões de saneamento e infiltração que observamos no quarto que seria do bebê. Reforçamos que deveríamos ser avisados sobre o nascimento, para podermos programar a visita mamãe-bebê, na primeira semana de vida.

Com relação a como esta estratégia pedagógica refletiu no processo de aprendizado do aluno, a pesquisadora/preceptora destaca em seu diário:

Quando conversamos na Unidade para colocar em debates a humanização na visita domiciliar relataram ter se sentido desconfortáveis durante a visita, sem saber como se comportar ou o que falar. Se mostraram surpresos com a quantidade de casas localizadas num espaço relativamente pequeno. Não imaginavam que ali teriam tantas casas, vielas e pessoas. Relatam também a importância de a equipe conhecer as condições da residência, das instalações, do saneamento local e de poder sugerir melhorias. 


\section{DISCUSSÃO}

A Discussão deste relato, foi realizada a partir do referencial teórico metodológico da análise institucional francesa e seus conceitos de instituído, instituinte, instituição, implicação (L'ABBATE S, et al. 2013). Na análise institucional, a técnica do Diário Institucional consiste na descrição de fatos relevantes ou marcantes em torno de uma vivência. O diário permite que se analisem os atravessamentos de diferentes instituições como a instituição família, a instituição religião, as instituições educação, saúde etc. presentes em um grupo e que se revelam nos depoimentos durante os debates, permitindo a análise das implicações dos participantes com estas instituições (HESS R, 1988; JESUS AF, et al., 2013).

O conceito de implicação é um dos mais relevantes para a análise institucional, referindo-se ao envolvimento sempre presente e até de natureza inconsciente com tudo aquilo que se faz. Para Barbier $R$ (1985) existem três níveis de implicação: o nível psicoafetivo, o histórico-existencial e o estrutural-profissional. A implicação psicoafetiva, ocorre em uma dimensão mais individual de acordo com as crenças, pertencimentos e valores. A implicação histórico-existencial, traz as questões relacionadas à classe social, aos hábitos adquiridos, a maneira de ver o mundo. A implicação estrutural profissional busca dar sentido no trabalho social, ligado aos aspectos socioeconômicos na sociedade contemporânea. (L'ABBATE S, et al. 2013; ROSSI A e PASSOS E, 2014; MOURÃO LC e SOASSUME T, 2015).

Com relação as implicações afetivas e profissionais da pesquisadora estas puderam ser constatadas nos relatos do diário com relação a quanto as instituições saúde e educação fazem parte do seu agir como pessoa e como médica por entender que a relação médico-paciente deve ocorrer a partir dos princípios de humanização e que esta maneira de agir deve ser parte da formação dos futuros profissionais. Esta posição da pesquisadora vem de sua concordância com os princípios do PNH onde se enfatiza a importância da relação médico-paciente na produção do cuidado, no acolhimento, na criação de vínculo, no incentivo à capacidade de decidir e de fazer escolhas com responsabilidade (BRASIL, 2004).

Quanto as implicações dos alunos com a formação e a humanização durante a consulta médica é importante destacar alguns aspectos: o primeiro com relação à pressa dos alunos em realizar o exame físico, que pode revelar práticas já instituídas na formação médica. Este posicionamento está coerente com um modelo de ensino-aprendizagem científico-positivista da cultura ocidental moderna, onde o médico detém o saber e define o que seria melhor para o seu paciente, considerando mais importante os exames complementares em detrimento do estado emocional, história familiar ou contexto social, desconsiderando uma visão global do paciente (NEVES SAVM, et al., 2016; VILAS BOAS LM, et al., 2017; RIOS IC, SIRINO $C B, 2015)$. Pode-se dizer que ainda existe um descompasso entre o que recomenda as DCN (BRASIL, 2014), ao enfatizar que se deve "favorecer a construção de vínculo, valorizando as preocupações, expectativas, crenças e os valores relacionados aos problemas relatados trazidos pela pessoa sob seus cuidados", e 0 ensino médico.

A segunda foi a mudança de posicionamento dos alunos que, após vivenciar a experiência, começaram a ter outra postura em relação à consulta médica, entendendo que o exame físico é apenas uma parte da mesma. Nos relatos do diário da pesquisadora/preceptora os alunos destacaram ser importante, durante a consulta, ter este momento de diálogo entre o médico e a paciente, estabelecendo entre eles uma relação amistosa, que promove a escuta qualificada, conferindo maior habilidade para lidar com as situações trazidas pelos pacientes, o que vem corroborar o que referem as DCN (BRASIL, 2014) e o PNH (BRASIL, 2004).

Estas observações remetem a Feuerwerker LCM (2011), ao referir que os profissionais devem proporcionar espaços para o diálogo, para que seja possível se conhecer as dificuldades e potencialidades das famílias, estabelecendo, com elas, pactos de responsabilidade para o cuidado à saúde. Devem-se, sobretudo, criar mecanismos e critérios para o acompanhamento dos usuários que possibilitem tirar dúvidas e reavaliar decisões.

Trazendo para discussão a segunda estratégia pedagógica, a visita domiciliar, algumas questões foram colocadas pela pesquisadora/preceptora nos debates de maneira a que os alunos pudessem refletir sobre sua prática a saber: Como percebem o papel do médico na Atenção Básica? De que maneira são abordadas, 
na graduação, as diferenças entre as classes sociais? Estes questionamentos vieram apoiados no que referem Alves CRL, et al., (2009) e Cotta RMM, et al., (2013), ao destacar que os alunos de Medicina são treinados a operar equipamentos e a fazer leituras de variáveis biológicas, sem espaço para desenvolverem habilidades e competências que os capacitem a reconhecer o ser humano como unidade biopsicossocial e espiritual, inserido em um contexto epidemiológico e sociocultural, na maioria das vezes diferente do que estão habituados.

Concorda-se com Rocha KB, et al (2017) de que a estratégia pedagógica visita domiciliar possibilitou que os alunos começassem a pensar além da lógica biomédica do sintoma, do problema, do risco, para ser pensada a partir da perspectiva também da promoção à saúde.

Pode-se dizer que a relevância desta estratégia foi aprofundar questões sociais e o conhecimento sobre a prática médica humanizada em diferentes espaços. Ficaram visíveis nesta estratégia pedagógica, as implicações pessoais e profissionais dos alunos com a educação médica ao revelarem como são pouco preparados para atuar em contextos onde as condições de vida e de trabalho dos indivíduos e de grupos da população afetam sua situação de saúde e, consequentemente, o agir do profissional médico nestes cenários.

Esta proposta pedagógica revelou que os debates sobre a formação médica, feita em interação com a população, transformam professores, profissionais e alunos que exercerão sua profissão na rede de saúde. Apontou, sobretudo, que as mudanças e adequações curriculares são necessárias e fundamentais para o aperfeiçoamento da prática médica mais humanizada. Ressalta-se que o principal desafio está na mudança de postura dos profissionais e de educadores, em suas práticas de ensino, para a formação dos futuros profissionais.

\section{CONSIDERAÇÕES FINAIS}

Vivenciar estas estratégias pedagógicas e colocar em análise as implicações com a formação e com a prática do cuidado humanizado permitiu aos alunos e preceptor entender os indivíduos como seres complexos e únicos, considerando sua formação social, cultural, ambiental e política.

\section{REFERÊNCIAS}

1. ALVES CRL, et al. Repercussões do Programa de Educação pelo Trabalho para a Saúde (PET-Saúde) na Reforma Curricular de Escolas Médicas Participantes do Programa de Incentivos às Mudanças Curriculares dos Cursos de Medicina (Promed). Revista Brasileira de Educação Médica. 2015; 39(4):527-36.

2. BARBIER R. Pesquisa-ação na instituição educativa. Rio de Janeiro: Zahar, 1985.

3. BRASIL. Ministério da Educação. Conselho Nacional de Educação. Câmara de Educação Superior. Resolução no 3 , de 20 de junho de 2014. Institui Diretrizes Curriculares Nacionais do Curso de Graduação em Medicina e dá outras providências. Brasília: Ministério da Educação, 2014.

4. BRASIL. Ministério da Saúde. Secretaria Executiva. Núcleo Técnico da Política Nacional de Humanização. Humaniza SUS: Política Nacional de Humanização Como Eixo Norteador das Práticas de Atenção e Gestão em Todas as Instâncias do SUS. Brasília. Ministério da Saúde; 2004.

5. BRASIL. Presidência da República. Casa Civil. Subchefia para Assuntos Jurídicos. Lei 8.080 de 19 de Setembro de 1990. Dispõe Sobre as Condições Para a Promoção, Proteção e Recuperação da Saúde, a Organização e o Funcionamento dos Serviços Correspondentes e dá Outras Providências. Brasília: Presidência da República, 1990.

6. COTTA RMM, et al. Debates atuais em humanização e saúde: quem somos nós? Ciênc. saúde coletiva. 2013; 18(1):171-9.

7. FEUERWERKER LCM. A cadeia do cuidado em saúde. In: MARINS JJ. (Org.). Educação, Saúde e Gestão. São Paulo: Hucitec; 2011. p. 99-113.

8. HESS R. Momento do diário e diário dos momentos. In: SOUZA EC, ABRAHÃO MHB, JOSSO MC. Tempos, narrativas e ficções: a invenção de si. Porto Alegre: EDIPUCRS, 2006.

9. JESUS AF, et al. O uso do diário como ferramenta estratégica da análise institucional para abordar o cotidiano do profissional de saúde: o caso do Dom Quixote. In: L'ABBATE S, MOURÃO LC, PEZZATO LM (Org.). Análise Institucional \& Saúde Coletiva. São Paulo: Hucitec. 2013. p. 206-39.

10. L'ABBATE S, et al. Análise Institucional e Saúde Coletiva. São Paulo: Hucitec, 2013.

11. MENEZES ML, SANTOS LRCS. Humanização na Atenção Primária à Saúde: um olhar sobre o trabalhador da saúde. Revista Saúde. 2017;13(1):786-96. 
12. MOURÃO LC, SOASSUME T. Reflexões sobre as ações do programa de hiperdia em centros de saúde: implicações profissionais. Diversitates. 2015; 7(2):34-43.

13. NEVES SAVM, et al. Estudo sobre o ensino de uma formação médica mais humana. Ciências Biológicas e da Saúde. 2016;37(2):39-46.

14. RIOS IC, SIRINO CB. A humanização no ensino de graduação em Medicina: o olhar dos estudantes. Revista Brasileira de Educação Médica, 2015;39(3):401-9.

15. ROCHA KB, et al. A visita domiciliar no contexto da saúde: uma revisão de literatura. Revista Psicologia, Saúde e Doenças. 2017;18(1):170-85.

16. ROSSI A, PASSOS E. Análise Institucional: revisão conceitual e nuances da pesquisa-intervenção no Brasil. Revista EPOS. 2014;5(1):156-81.

17. SANTOS JUNIOR CJ, et al. Educação médica e formação na perspectiva ampliada e multidimensional: considerações acerca de uma experiência de ensino-aprendizagem. Revista Brasileira de Educação Médica. 2019; 43(1):72-9.

18. SILVA LA, et al. Ensino médico e humanização" Psicologia Argumento. 2015;33(80):298-309.

19. VILAS BOAS LM, et al. Educação Médica: Desafio da Humanização na Formação. Saúde em Redes. 2017;3(2):172182. 